\title{
RANCANGAN PEMBELAJARAN KASUS BERBASIS E-LEARNING UNTUK ASUHAN KEPERAWATAN MATERNITAS DENGAN PENDEKATAN TAKSONOMI NANDA-I, NIC, NOC
}

\author{
Hidayah ${ }^{1}$, Lutfan Lazuardi ${ }^{2}$, Wiwin Lismidiati ${ }^{3}$ \\ ${ }^{1}$ Mahasiswa Program Studi Magister Keperawatan, \\ Fakultas Kedokteran Universitas Gadjah Mada \\ 2Departemen Kebijakan dan Manajemen Kesehatan, \\ Fakultas Kedokteran Universitas Gadjah Mada \\ ${ }^{3}$ Departemen Keperawatan Anak dan Maternitas, \\ Fakultas Kedokteran Universitas Gadjah Mada \\ E-mail: hidayahaya1@gmail.com
}

\begin{abstract}
ABSTRAK
Tujuan Penelitian: Mendeskripsikan kebutuhan pengguna untuk merancang pembelajaran kasus berbasis e-learning dengan menggunakan pedoman NANDA-I, NIC, NOC dalam asuhan keperawatan maternitas. Metode: Desain penelitian yang digunakan ialah metode kualitatif dengan pendekatan studi deskriptif analitik. Proses pengambilan sampel dengan cara purposive sampling. Partisipan terdiri atas 2 orang dosen dan 5 orang mahasiswa. Penelitian dilakukan pada bulan November 2015 selama 3 minggu. Analisis data dengan pendekatan kualitatif dan penyajian data dilakukan secara deskriptif. Hasil Penelitian: Hasil penelitian terdiri atas 4 tema utama, yaitu (1) permasalahan dalam proses pembelajaran asuhan keperawatan maternitas dengan menggunakan pedoman NANDA-I, NIC, NOC baik yang berasal dari mahasiswa, dosen, maupun sistem pembelajaran. Permasalahan meliputi pengajaran asuhan keperawatan belum seluruhnya menggunakan NANDA-I, NIC, NOC, ketidakpahaman mahasiswa menggunakan NANDA-I, NIC, NOC jika diberikan kasus, fasilitas buku perpustakaan terkait NANDA-I, NIC, NOC terbatas dan kurang lengkap; (2) tujuan pembelajaran asuhan keperawatan maternitas dengan menggunakan pedoman NANDA-I, NIC dan NOC; (3) tujuan pengembangan prototype e-learning, (4) spesifikasi rancangan prototype E-learning yang dibutuhkan pengguna yang meliputi tampilan user friendly dan menarik; konten yang diinginkan berupa latihan penyelesaian kasus; kasus yang terdiri atas DM gestasional, preeklampsi, eklampsi, sindrom HELLP, solutio plasenta, perdarahan antepartum, dan masalah sistem reproduksi. Sistem pengamanan berupa password dan account, serta dilengkapi proses download serta fleksibel dan kompatibel. Diskusi: Faktor penyebab utama adanya masalah dalam pembelajaran asuhan keperawatan dengan menggunakan NANDA-I, NIC, NOC, karena fokus pembelajaran yang lebih ditekankan pada pengumpulan pengetahuan tanpa mempertimbangkan keterampilan dalam melakukan asuhan keperawatan. Fokus rancangan prototype pembelajaran kasus berbasis e-learning ini untuk selanjutnya bertumpu pada tampilan antarmuka serta pilihan skenario kasus yang dapat mengakomodasi kebutuhan mahasiswa dalam pembelajaran kasus. Kesimpulan: Pengembangan rancangan prototype pembelajaran kasus berbasis e-learning ini ditujukan sebagai pelengkap pembelajaran konvensional yang berfokus pada aspek pengetahuan mahasiswa dalam menerapkan penggunaan NANDA-I, NIC, NOC melalui latihan-latihan kasus yang diberikan.

Kata Kunci: E-learning, asuhan keperawatan maternitas, NANDA-I, NIC, NOC
\end{abstract}

THE DEVELOPMENT OF E-LEARNING-BASED CASE LEARNING FOR MATERNITY NURSING CARE USING NANDA-I, NIC, NOC TAXONOMY APPROACH

ABSTRACT

Objective: To describe the development of E-learning-based case learning using the guidelines taken from NANDA-I, NIC, NOC for maternity nursing care. Methods: This study was conducted using a qualitative method with decsriptive analytical approach. Samples were taken using purposive sampling technique. Participants consisted of two lectures and five students. The study was conducted in November 2015 for three weeks. Data were analyzed qualitatively and presented 
descriptively. Results: The results of the study consisted of four major themes: (1) problems in maternity nursing care learning process by using the guidelines taken from NANDA-I, NIC, NOC from students, lecturers and learning systems. The problems were that not all teachings of nursing care used NANDA-I, NIC, NOC, students did not understand using NANDA-I, NIC, NOC if case were given, books related to NANDA-I, NIC, NOC in the library were limited and incomplete, (2) Objectives of maternity nursing care learning by using the guidelines taken from NANDA-I, NIC and NOC,

(3) Objectives of the development of E-learning prototype, (4) Specification of E-learning prototype required by users such as user-friendly and interesting interface, contents consisting of case exercises, cases including gestational DM, pre-eclampsia, eclampsia, HELLP syndrome, placenta solution, antepartum hemorrhage and reproduction system problems. Security system applied password and account accompanied with a flexible and compatible download page. Discussion: Problems arose in nursing care learning which employed NANDA-I, NIC, NOC because the learning process focused on collecting knowledge without taking skills in performing nursing care into consideration. The development of E-learning-based case learning prototype was focused on interface and the options of case scenario that can accommodate students' requirements in the case learning. Conclusion: E-learning-based case learning prototype was developed as a complementary media for the conventional learning which focused on the cognitive aspects of students in employing NANDA-I, NIC, NOC through case exercises provided.

Keywords: E-learning, Maternity Nursing Care, NANDA-I, NIC, NOC

\section{LATAR BELAKANG}

Pendidikan keperawatan sebagaiinstitusi yang mengembangkan dan menciptakan tenaga keperawatan memiliki peran sangat besar dalam pembentukan profesionalisasi keperawatan (Inayatullah dkk., 2014). Profesionalisasi keperawatan tersebut dapat terlihat dari salah satu kontribusi besar yang diberikan perawat dalam sistem pelayanan kesehatan, yaitu melalui pemberian asuhan keperawatan yang berkualitas kepada klien. Peran perawat dalam pemberian asuhan keperawatan tersebut ialah memenuhi kebutuhan dasar klien dengan menggunakan proses keperawatan (Amalia \& Haryati, 2013). Untuk mendapatkan asuhan keperawatan yang efektif dan efesien diperlukan suatu standar sebagai acuan dalam melaksanakan asuhan keperawatan (Florensa dkk., 2009).

Menurut Park (2010), saat ini terdapat 12 standar bahasa keperawatan dan elemen set data, yang diakui oleh Asosiasi Perawat Amerika yang diterapkan untuk menggambarkan asuhan keperawatan, di antaranya NMDS (Nursing Minim Data Set), ICNP (International Classification of
Nursing Practice), SNOMED-CT, NANDA-I, NIC, PCDS (Patient Care Data Set), ABC Codes, CCC (Clinical Care Classification). Mahasiswa keperawatan yang dipersiapkan untuk menjadi praktisi berpendidikan yang profesional ini diharapkan mempunyai kemampuan intelektual untuk memilih dan menerapkan asuhan keperawatan yang sesuai dengan teori dan penggunaan istilah yang terstandardisasi (Muller-Staub dkk., 2008). Di antara dua belas terminologi keperawatan standar yang ada, NANDA-I, hasil NOC dan intervensi NIC dipilih dalam penelitian ini karena bahasa ini digunakan di banyak setting pelayanan kesehatan sebagai sarana berkomunikasi yang lebih efektif antara perawat serta memiliki penetrasi paling luas dalam pola penyebarannya dibandingkan lima terminologi keperawatan lainnya seperti: CCC, ICNP, sistem OMAHA, PNDS (Park, 2010). Selain itu, sistem NANDA, NOC, dan NIC dapat diterima dan mendukung semua bagian proses keperawatan, kecuali pengkajian. NANDA, NOC, dan NIC didukung oleh penelitian dan memfasilitasi perawatan lanjutan pada 
semua area keperawatan (Florensa dkk., 2009).

Rendahnya penguasaan mahasiswa terhadap asuhan keperawatan akan berdampak pada terhambatnya pengembangan dan adaptasi bahasa standar bagi mahasiswa dan dosen (Kautz dkk., 2006). Tanpa istilah dan bahasa yang terstandarisasi, dokumentasi asuhan keperawatan akan menjadi tidak spesifik dan ambigu. Hal ini akan berdampak pada ketidakpastian dan gangguan dalam pertukaran informasi sehingga mengakibatkan terputusnya pemberian pelayanan keperawatan (Aprisunadi, 2011).

Pendidikan tinggi keperawatan dalam hal ini adalah dosen perlu mencari cara untuk dapat melakukan modifikasi terkait prinsipprinsip pedagogis dan metode pembelajaran mandiri yang berpusat pada mahasiswa. Hal inimengingatasuhankeperawatanmaternitas dengan pendekatan taksonomi NANDA-I, NIC, NOC membutuhkan pemahaman khusus untuk menginternalisasikan dan melakukan tahapan-tahapan asuhan keperawatan maernitas. Salah satu cara untuk membentuk pemahaman ini ialah dengan memvisualisasikan materi tersebut ke dalam bentuk media pembelajaran digital guna membantu penggambaran materi tertulis sehingga persepsi untuk materi tersebut lebih mudah untuk dibentuk dan dipahami.

E-learning sebagai pembelajaran jarak jauh, diharapkan akan membawa pengaruh terhadap proses transformasi pendidikan konvensional ke dalam bentuk digital, baik isi maupun sistemnya (Tabanan dkk., 2014). Hal ini dibuktikan dengan hasil penelitian Hariyati, dkk., (2011) disebutkan bahwa secara umum, tujuan pengembangan pembelajaran jarak jauh yang dilakukan adalah untuk menjembatani praktisi kesehatan yang sudah memiliki kemampuan, infrastruktur, dan motivasi untuk belajar, tetapi tidak memiliki kesempatan untuk mendapatkan pendidikan formal yang lebih tinggi. Metode pembelajaran jarak jauh dipilih dengan alasan bahwa hal tersebut memungkinkan proses belajar tanpa dibatasi oleh waktu dan tempat tertentu. Lebih penting lagi adalah metode tersebut memungkinkan mereka untuk belajar secara mandiri.

Dukungan kapasitas jaringan yang dimiliki STIK Muhammadiyah Pontianak yaitu sebesar 20 mbps dengan 553 mahasiswa dari 917 keseluruhan total mahasiswa S-1 dan D-3 yang terdaftar sebagai pengguna internet, adanya website kampus dengan alamat www.stikmuhptk.ac.id, tersedianya fasilitas IT di kelas untuk menunjang pembelajaran dengan jenis hotspot berjumlah $17 \mathrm{kbps} / \mathrm{mahasiswa}$ dan alokasi jaringan free wifi dengan kapasitas $10 \mathrm{kbps} /$ account sudah selayaknya menjadi peluang bagi berkembangnya proses pembelajaran yang memanfaatkan fasilitas online baik sebagai pelengkap, penunjang maupun tambahan dalam kegiatan belajar-mengajar.

Tujuan penelitian ini ialah mendeskripsikan kebutuhan pengguna untuk merancang pembelajaran kasus berbasis e-learning dengan menggunakan pedoman NANDA-I, NIC, NOC dalam asuhan keperawatan maternitas.

\section{METODE}

Rancangan penelitian ini ialah metode kualitatif dengan pendekatan studi deskriptif analitik. Teknik pengambilan sampel yang digunakan ialah purposive sampling. Partisipan berjumlah 7 orang terdiri atas 2 orang dosen pengampu mata kuliah sistem reproduksi dan 5 orang mahasiswa program studi S-1 Keperawatan semester V. Instrumen yang digunakan dalam penelitian ini ialah panduan wawancara mendalam yang terdiri atas 17 pertanyaan terbuka, 
panduan observasi, studi dokumentasi. Penelitian dilakukan di STIK Muhammadiyah Pontianak selama 3 minggu pada bulan November 2015. Analisis dan penyajian data dalam penelitian ini dilakukan dengan teknik analisis deskriptif kualitatif.

\section{HASIL PENELITIAN}

Terdapat empat tema utama yang ditemukan dari penelitian tentang rancangan pembelajaran kasus berbasis e-learning untuk asuhan keperawatan maternitas dengan menggunakan pedoman NANDA-I, NIC, NOC.

\section{Permasalahan dalam proses pembelajaran asuhan keperawatan maternitas dengan menggunakan pedoman NANDA-I, NIC, NOC}

Masalah yang berasal dari individu proses pembelajaran khususnya dosen adalah pengajaran asuhan keperawatan belum seluruhnya menggunakan NANDA-I, NIC, NOC. Hal ini dapat dilihat dari ungkapan partisipan sebagai berikut.

“...Tim pengajaran juga yang mungkin masih belum seluruhnya menggunakan NANDA, NIC dan NOC tadi." (D.IE)

Berdasarkan hasil observasi dan studi dokumentasi yang dilakukan diperoleh metode pembelajaran yang digunakan dengan ceramah dan diskusi tanya jawab serta penggunaan media pembelajaran yang terbatas hanya pada media power point dengan bantuan $L C D$. Konsep materi yang dijelaskan dalam waktu 100 menit terdiri atas dua materi yang berhubungan dengan asuhan keperawatan maternitas.

Masalah yang berasal dari mahasiswa di antaranya ialah ketidakpahaman mahasiswa menggunakan NANDA-I, NIC, NOC jika diberikan kasus, penggunaan literatur online yang kurang dapat dipertanggungjawabkan, bosan terhadap metode pembelajaran, serta rendahnya kesadaran memiliki buku NANDA-I, NIC, NOC. Hal ini sesuai dengan kutipan hasil wawancara dengan partisipan sebagai berikut.

“...Tapi, mereka kurang paham menggunakannya. Begitu kita pake buku yang pisah NANDA, NIC, NOC sendiri..." (D.S)

"Kalo selama ini dariii, paling medianya kan kita disuruh siapkan buku NANDA, NIC, NOC. Buka NANDA, NIC,NOC udah itu aja bu. Jadinya tidak puas. Karena ya..apa namanya bosan dengan seperti itu. Abis itu ribet menurut saya." (M.R)

Masalah yang berasal dari sistem ialah fasilitas buku perpustakaan terkait NANDA-I, NIC, NOC terbatas dan kurang lengkap, literatur yang tersedia saat ini lebih mendekati Doengoes, belum tersedia media pembelajaran khusus asuhan keperawatan maternitas dengan NANDA-I, NIC, NOC. Hal tersebut sesuai dengan kutipan hasil wawancara dengan partisipan sebagai berikut:

“...Karena mungkin keterbatasan literatur tadi, apalagi dengan jumlah mahasiswa yang mungkin cukup banyak, dengan fasilitas buku yang ada di perpustakaan yang cukup terbatas..."

"...di buku-buku itu tadi lebih mendekati dengan Doengoes...." (D.IE)

“...Kemudian apa, kayak di perpus kita pun kan agak-agak kurang lengkap juga kan ...." (M.KI) 
“...belum ada secara spesifik penggunaan media pembelajaran yang khusus untuk memberikan pembelajaran asuhan keperawatan maternitas dengan menggunakan NANDA, NIC, NOC." (M.J)

\section{Tujuan pembelajaran asuhan keperawatan maternitas berbasis E-learning dengan menggunakan pedoman NANDA-I, NIC, NOC}

Berdasarkan hasil wawancara yang dilakukan teridentifikasi tujuan pembelajaran asuhan keperawatan maternitas dengan menggunakan pendekatan taksonomi NANDA-I, NIC dan NOC berdasarkan harapan dosen dan mahasiswa adalah mahasiswa dapat mengerti dan memahami penggunaan NANDA-I, NIC, dan NOC dalam asuhan keperawatan maternitas serta mampu mengaplikasikan penggunaan NANDA, NIC, dan NOC di dalam E-learning melalui tugas-tugas yang diberikan. Hal ini seperti diungkapkan oleh partisipan sebagai berikut:

“...dengan media E-learning yang akan, terutama untuk NANDA, NIC, NOC untuk perkuliahan asuhan keperawatan maternitas sangaat membantu sekali nanti dalam pemahaman terutama mahasiswa terhadap itu tadi, penggunaan NANDA, NIC, NOC tadi..."(D.IE)

“...karena lebih praktis, lebih mudah kita eee ibaratnya dalam artian kita pergunakan e-learning ada tugas-tugas langsung bisa dikerjakan di sana. Terus bagi teman-teman yang tidak ada NANDA, NIC, NOC jadi lebih mudahkan."(M.R)

\section{Tujuan pengembangan prototype $E$ learning}

Berdasarkan hasil wawancara yang dilakukan teridentifikasi tujuan pengembangan prototype e-learning adalah sebagai pelengkap pembelajaran konvensional yang berfungsi sebagai sarana penugasan kasus, memfasilitasi materi pengantar sebelum masuk kelas, memperjelas materi dan media untuk konsultasi dan diskusi. Hal ini seperti yang diungkapkan oleh partisipan sebagai berikut.

“...sebagai materi perkuliahan juga, dia juga disitu bisa sebagai media bagi mahasiswa untuk menyelesaikan kasuskasus yang ada...." (D.IE)

“...Untuk pelengkap, kan, ibaratnya ini dapat memudahkan teman-teman yang males untuk mempelajari penggunaan NANDA, NIC, NOC dalam asuhan keperawatan maternitas." (M.R)

"...Sebelum kita masuk di kelas kita buka E-learning dulu baru dosen menyampaikan. Jadi kita sudah punya bekal dulu sebelum dosen menjelaskan...." (M.J)

“...jadi materi itu selesai dahulu, dia sudah paham. Penugasannya seperti apa silahkan dikerjakan. Bisa konsultasi tadi via online. Tidak masuk tugasnya, tidak ada konsultasi, maka tidak ada nilai." (D.S)

\section{Spesifikasi rancangan prototype} E-learning yang dibutuhkan pengguna Berdasarkan hasil wawancara yang dilakukan teridentifikasi bahwa dosen merasa perlu adanya media pembelajaran yang dapat membantu proses pembelajaran serta kemampuan mahasiswa dalam memahami penggunaan NANDA, NIC dan NOC. Hal ini seperti diungkapkan melalui pernyataan partisipan sebagai berikut:

“...sepertinye perlu kali ye, kalaupun nanti misalnya, akhirnya nanti ada 
media pembelajaran yang mungkin akan membantu terhadap proses pembelajaran dan pemahaman dari tim pengajaran dan mahasiswa mampu untuk memahami penggunaan NANDA, NIC, dan NOC tersebut." (D.IE)

Spesifikasi model prototype yang diperlukan pengguna dalam pengembangan diantaranya adalah: tampilan E-learning yang dibuat menarik, diberikan lambang EL-MNP serta cover E-learning yang akrab dengan mahasiswa. Seperti yang diungkapkan oleh partisipan sebagai berikut:

"Kalo menurut saya, dibuat menariklah bu. Tampilannya dibuat beda...." (M.K1).

“...Tampilannye. Setidaknya E-learning punya lambang tersendiri..." (M.KI)

"...Kita terkait dengan ee ape ye namenye, coverlah seperti itu yang akrab dengan mahasiswa..." (M.T)

Kebutuhan konten yang harus ada dalam prototype E-learning adalah adanya contoh kasus dan ilustrasi penyelesaian kasus menggunakan NANDA-I, NIC, NOC, latihan kasus yang diberikan untuk mahasiswa melalui e-learning. Hal ini seperti diungkapkan oleh partisipan sebagai berikut:

“...Apalagi ye? Asuhan keperawatan (diam sejenak) eee dalam ini, dalam pembelajaran. Kasus kali ye. Kayaknya kalo saya sih memang enaknye pertame kemudahan untuk mahasiswa mengangkat diagnosanye, terus abis itu untuk dia. menentukan intervensi..." (D.S)

“...Kasus, kita langsung eeee emmm kita langsung ada kasus, terus kita identifikasi lalu kita hubungkan langsung dengan
NANDA, NIC, NOC. Kalo menurut saya itu lebih efektif." (M.R)

Skenario kasus yang dibutuhkan untuk dihadirkan dalam prototype E-learning berkaitan dengan perdarahan antepartum, solutio plasenta, pre eklampsi, eklampsi, sindrom HELLP, masalah sistem reproduksi, DM Gestasional. Hal ini seperti yang diungkapkan oleh partisipan sebagai berikut:

“...kayak askep ibu dengan DM gestational gitu, Bu. Terus ibu dengan apa namanya preeklampsi, eklampsi gitu, Bu. Terus apa lagi ya, sindrom HEELP." (M.D)

“...misal perdarahan antepartum...."(M.J)

"Salah satunya solutio plasenta..."(M. TH)

Berdasarkan hasil wawancara yang dilakukan, e-learning yang diharapkan perlu memperhatikan sistem keamanan dengan menggunakan password dan account, dapat download file/materi serta dapat digunakan di mana pun untuk belajar asuhan keperawatan maternitas dengan NANDA-I, NIC, NOC serta dapat digunakan melalui handphone. Hal ini seperti yang diungkapkan oleh partisipan sebagai berikut:

“...Kemudian akan lebih asyik lagi, Bu, kalo misal ada, bisa kalo ada member gitu bu. Kita bisa saling tukar pendapat sesama member. Otomatis dengan adanya member bisa ada password sama account juga yah. "...Kalo bise ada itu, Bu, ada ape namenye tuh, bisa kita download itu bu..." (M.J)

“...Yah walaupun kadang kita juga punya buku dan sebagainya, tetapi kan terkadang yang namanya buku ya berat juga kadang dibawa terus-terusan. Dan itu juga menunjang, menunjang dalam artian apa, 
misalkan di kelas ada HP ada aplikasinya itu sangat memudahkan atau membantu sekali..." (M.TH)

"...Tetapi kalo dilihat dari sisi $\mathrm{mmm}$ kemudahan yah. Udah pakek internet semuanya bisa akses itu lebih mudah, dimana saja bisa digunakan atau dimana saja bisa dapat informasi. Pun saya juga ngajarnya jadi lebih mudah kan pakek itu." (D.S)

\section{DISKUSI}

1. Permasalahan dalam proses pembelajaran asuhan keperawatan maternitas dengan menggunakan pedoman NANDA-I, NIC, NOC

Hasil analisis yang ditemukan pada tahap identifikasi, kebutuhan pengguna berkaitan dengan permasalahan dalam proses pembelajaran asuhan keperawatan maternitas dengan menggunakan NANDA-I, NIC dan NOC. Hal itu menunjukkan bahwa metode pengajaran yang diterapkan oleh dosen pada saat ini masih menggunakan metode konvensional dan belum ada kesepakatan antara pengajar dalam hal penggunaan NANDA-I, NIC, dan NOC dalam asuhan keperawatan maternitas. Hal ini disebabkan metode ini dinilai lebih praktis, mudah dilaksanakan, dan tidak perlu peralatan yang dilakukan untuk mengajar mahasiswa yang jumlahnya relatif besar.

Temuan yang diperoleh peneliti tidak jauh berbeda dengan hasil penelitian yang dilakukan oleh Agrina dkk. (2012), bahwa penerapan metode pengajaran pada mata kuliah keperawatan keluarga khususnya asuhan keperawatan keluarga adalah dengan menggunakan metode ceramah dan diskusi kelompok sesuai dengan kasus yang diambil oleh mahasiswa. Selain itu, terkait dengan penggunaan NANDA-I, NIC dan NOC menurut Yearous (2010), hambatan dalam menggunakan standar bahasa keperawatan NANDA-I, NIC, dan NOC ialah kurangnya pemahaman standar bahasa keperawatan oleh dosen dan mahasiswa, kurangnya kebijakan dari sistem pendidikan dalam menggunakan standar bahasa keperawatan, kurangnya mentor untuk memfasilitasi penggunaan standar bahasa keperawatan.

Berdasarkan temuan penelitian dan kesesuaian dengan penelitian sebelumnya dapat disimpulkan bahwa faktor penyebab utama adanya masalah dalam pembelajaran asuhan keperawatan dengan menggunakan NANDA-I, NIC, NOC disebabkan fokus pembelajaran yang lebih ditekankan pada pengumpulan pengetahuan tanpa mempertimbangkan keterampilan dalam melakukan asuhan keperawatan.

Permasalahan yang dialami oleh dosen dan mahasiswa juga tidak dapat dilepaskan dari sistem yang diterapkan dalam proses pembelajaran dan sarana pendukung proses pembelajaran yang memfasilitasi pemahaman mahasiswa tentang penggunaan NANDA-I, NIC dan NOC. Selain itu, konsistensi, minat, dan perhatian mahasiswa untuk belajar secara langsung atau tidak langsung terhadap penggunaan NANDA-I, NIC, dan NOC dalam asuhan keperawatan maternitas juga menjadi fokus perhatian sehubungan dengan permasalahan yang teridentifikasi.

Hasil penelitian tersebut hampir sama dengan penelitian yang dilakukan oleh Yearous (2010), hambatan dalam pembelajaran standar bahasa keperawatan NANDA-I, NIC, dan NOC di antaranya adalah kurangnya pengetahuan berhubungan dengan standar bahasa keperawatan; waktu untuk mempelajari penggunaan bahasa standar dalam dokumentasi asuhan keperawatan yang kurang; dokumentasi saat ini tidak termasuk standar bahasa 
keperawatan NANDA-I, NIC, dan NOC; kurangnya buku referensi seperti buku NANDA-I, NIC, dan NOC; kesadaran untuk mengubah praktik dokumentasi asuhan keperawatan dengan menggunakan standar bahasa keperawatan yang rendah.

Menurut Kaesmetan dan Rochdiyat (2012), sebanyak 34,8 persen (23 responden dari 66 responden mahasiswa FIKES UNRIYO semester IV) memiliki penguasaan yang baik terhadap penggunaan NANDA-I, NIC, dan NOC. Namun, itu artinya belum semua responden memiliki penguasaan NANDA-I, NIC, dan NOC yang baik.

\section{Tujuan pembelajaran dan pengembangan asuhan keperawatan maternitas berbasis E-learning dengan menggunakan pedoman NANDA-I, NIC, NOC}

Permasalahan yang ditemukan dalam proses pembelajaran asuhan keperawatan maternitas dengan menggunakan NANDA-I, NIC, dan NOC, perlu dicarikan solusi alternatif yang dapat membantu mahasiswa aktif dalam memahami asuhan keperawatan maternitas dengan menggunakan pedoman NANDA-I, NIC, dan NOC. Sebelum pengembangan dilakukan, perlu diketahui tujuan pembelajaran agar dapat memfasilitasi konsep rancangan yang akan dikembangkan berdasarkan kebutuhan pengguna dengan tetap memperhatikan kompetensi yang diharapkan serta kurikulum di dalam pembelajaran.

Temuan penelitian ini jelas tidak bertentangan dengan hasil penelitian yang dilakukan oleh Gerdprasert dkk. (2009), bahwa unit pembelajaran berbasis web ini dirancang dengan baik dan relevan dengan kurikulum yang memfasilitasi belajar mahasiswa keperawatan tentang proses dan mekanisme persalinan. Topik pengembangan masing-masing penelitian berbeda karena berkaitan dengan karakteristik dan kebutuhan institusi dalam pengembangan. Akan tetapi, dapat disimpulkan bahwa untuk merencanakan pembelajaran berbasis web tentunya juga harus didukung dengan kurikulum yang relevan agar sesuai dengan tujuan pembelajaran yang diharapkan, yaitu pengetahuan dan pemahaman mahasiswa tentang asuhan keperawatan maternitas meningkat. Hal ini sesuai dengan penelitian Sukismanto dan Rahayu (2012) bahwa kebutuhan e-learning dalam penelitiannya hendaknya sebagai penunjang mata kuliah sesuai kuikulum yang berlaku. Menurut Ramdani dan Murdani (2014), dengan menerapkan RPP yang telah dibuat, maka secara kualitatif diharapkan dapat mewakili E-learning yang berfungsi sebagai pelengkap materi pembelajaran. Tujuannya agar semakin memantapkan tingkat penguasaan peserta didik terhadap materi pelajaran yang diterima di kelas serta menuntut keaktifan dan kreativitas peserta didik.

Fakta lainnya yang ditemukan dalam penelitian ini ialah bahwa tujuan pengembangan e-learning yang diharapkan pengguna sebaiknya di tahap awal berfungsi sebagai pelengkap pembelajaran konvensional. Hal ini sangat sesuai, mengingat proses yang dilakukan dalam penelitian ini selanjutnya merupakan tahap awal pengembangan dan merupakan hal yang sangat baru. Hal ini sejalan dengan hasil penelitian Hariyati dkk. (2011), bahwa responden sangat setuju (80 persen) pembelajaran berbasis IT dapat menjadi metode pembelajaran alternatif.

Hasil penelitian Sukismanto dan Rahayu (2012) menjelaskan bahwa pada tahap identifikasi kebutuhan sebanyak 99 persen pengguna menyatakan setuju apabila desain e-learning digunakan sebagai penunjang pembelajaran. Menurut Ramdani dan Murdani (2014), pada awalnya tujuan 
e-learning diproyeksikan sebagai pengganti metode pembelajaran konvensional, tapi kenyataannya sampai saat ini e-learning belum dapat menggantikan peran dan keuntungan dari metode pembelajaran konvensional. Akibatnya, sampai saat ini e-learning lebih cocok berperan sebagai pelengkap bagi metode pembelajaran konvensional.

Konsep pemanfaatan e-learning seperti ini dianggap memberikan efek resiko paling rendah dibandingkan dengan desain yang lain dan memberikan efek pembelajaran yang banyak. Hal ini sesuai dengan penelitian Fathurrohman dkk. (2011), bahwa pengaruh desain model pembelajaran e-learning dengan koefisien korelasi parsial 0,326 sangat jelas menunjukkan kontribusi yang cukup besar terhadap prestasi belajar mahasiswa FK Unimus pada mata kuliah parasitologi. Hasil penelitian tersebut juga sejalan dengan Hariyati dkk. (2011) yang menyebutkan bahwa responden sangat setuju (85 persen) pembelajaran berbasis IT dapat meningkatkan pengetahuan dan perspektif.

Analisis kebutuhan yang dilakukan dalam penelitian ini pada dasarnya belum menemukan pernyataan dari responden yang mengindikasikan dibutuhkan atau tidaknya pengembangan prototype E-learning asuhan keperawatan maternitas dengan pendekatan taksonomi NANDA-I, NIC dan NOC. Namun, ada sejumlah faktor pendukung yang dapat dijadikan sebagai dasar untuk melakukan pengembangan prototype E-learning tersebut dengan mengacu pada hasil analisis yang diperoleh saat wawancara.

Peneliti menyimpulkan bahwa faktor yang memengaruhi tidak teridentifikasinya pernyataan tersebut, bisa disebabkan oleh pertanyaan yang diberikan pada saat wawancara tidak spesifik. Hal ini mengakibatkan peneliti belum berhasil dalam menggiring responden terhadap pernyataan yang akan membuktikan bahwa pengguna membutuhkan pengembangan prototype e-learning tersebut.

\section{Spesifikasi rancangan prototype E-learning yang dibutuhkan pengguna} Kebutuhan pengguna akan konten berupa kasus menjadi prioritas yang paling penting bagi dosen dan mahasiswa. Hal ini bertujuan untuk memudahkan dalam memahami asuhan keperawatan maternitas dengan menggunakan pedoman NANDA-I, NIC, dan NOC. Keberadaan kasus dalam pengembangan pembelajaran berbasis e-learning ini sangat tepat jika diterapkan dalam pembelajaran asuhan keperawatan maternitas. Hal ini sejalan dengan penelitian yang dilakukan oleh Agrina dkk. (2012), bahwa penerapan metode drill dengan studi kasus sangat cocok diterapkan pada mata kuliah keperawatan keluarga dalam proses belajar mengajar dan dirasakan sangat efektif.

Hal ini juga serupa dengan penelitian yang dilakukan oleh Goes dkk., (2012), bahwa untuk mengakomodasi kebutuhan mahasiswa akan pemahaman kasus asuhan keperawatan, juga dihasilkan sejumlah konten teoretis terkait diagnosis keperawatan maupun persentasi otomatis mengenai 3 kasus klinis bayi baru lahir serta 4 simulasi latihan kasus bayi baru lahir prematur.

Meskipun kedua hasil temuan ini memiliki tujuan yang berbeda, namun konsep rancangan yang dihasilkan berdasarkan penelusuran literatur yang dilakukan masingmasing peneliti hampir sama. Hanya saja dalam proses perencanaan, peneliti tidak bisa mengabaikan kebutuhan pengguna karena rancangan yang dihasilkan oleh peneliti dalam proses pengembangan sangat tergantung pada karakteristik pembelajar 
maupun karakterisik institusi itu sendiri.

Fokus pengembangan e-learning pada penelitian ini, untuk selanjutnya bertumpu pada tampilan antarmuka, berupa latihan dan skenario kasus dalam bentuk case study. Fitur ini bisa saja berisi skenario kasus dan petunjuk pengerjaan soal menggunakan pedoman NANDA-I, NIC dan NOC yang dimasukkan ke dalam lingkungan pembelajaran di internet. Portal e-learning yang dihasilkan nantinya diharapkan dapat diakses secara online oleh pengguna.

\section{SIMPULAN}

Berdasarkan hasil penelitian dan pengembangan yang dijabarkan, maka dapat dikemukakanbeberapakesimpulanpenelitian yaitu bahwa tahap identifikasi kebutuhan tidak hanya berkaitan dengan diperlukan atau tidaknya suatu pengembangan dilakukan, tetapi juga berkaitan dengan permasalahan yang berhubungan dengan aktivitas pembelajaran asuhan keperawatan maternitas dengan pedoman NANDA-I, NIC, dan $N O C$, tujuan pembelajaran berbasis e-learning, tujuan pengembangan, maupun spesifikasi model yang dibutuhkan. Penting untuk mempertimbangkan keterlibatan pengguna dalam proses perancangan dan pengembangan agar dapat diperoleh masukan untuk penyempurnaan dari prototype serta mendukung keberhasilan dari pelaksanaan pengembangan itu sendiri.

\section{DAFTAR PUSTAKA}

Agrina, Zulfitri, R., dan Herlina. 2012. "Metode Drill Studi Kasus dalam Meningkatkan Hasil Belajar Asuhan Keperawatan Keluarga". Jurnal Keperawatan, 3(2), 113-119.

Amalia, W.A. dan Hariyati, R.T.S. (2013). Hubungan Karakteristik Perawat dengan Pengetahuan Perawat tentang Proses Keperawatan dan Diagnosis NANDA. Skripsi, Universitas Indonesia, Jakarta.
Aprisunadi. 2011. Hubungan antara Berfikir Kritis Perawat dengan Kualitas Asuhan Keperawatan di Unit Perawatan Ortopedi Rumah Sakit Umum Pusat Fatmawati Jakarta. Thesis. Universitas Indonesia, Jakarta. Retrieved from: lib. ui.ac.id/file?file=digital/20280242-T\%20 Aprisunadi.pdf. Diakses tanggal 6 Mei 2015.

Fathurrohman, A., Syukur, A., dan Subagyo, H. 2011. "Pengaruh Pengembangan Model Pembelajaran E-Learning pada Fakultas Kedokteran Universitas Muhammadiyah Semarang". Tesis. Universitas Muhammadiyah Semarang, Semarang.

Florensa, Nurjannah, I. dan Rahmat, I. (2009). Gambaran Asuhan Keperawatan pada Klien Jiwa dengan Perilaku Kekerasan Dikaitkan dengan Diagnosis NANDA, NOC, dan NIC. Jurnal IImu Keperawatan, 04 (01), 32-36.

Gerdprasert, S., Pruksacheva, T., Panjipan, B., Ruenwongsa, P. 2009. "Development of A Web Based Learning Medium on Mechanism of Labour For Nursing Students". Nurse Education Today Journal, (30), 461-469. doi:10.1016/j. nedt.2009.10.007.

Goes, F.D.S.N.D.E., Fonseca, L.M.M., Leite, A.M., Furtado, M.C.D.C., Scochi, C.G.S. 2012. "Development and Evaluation of An Interactive Virtual Learning Object on the Diagnostic Reasoning in Nursing Applied to Preterm Newborns". Procedia-Soc. Behav. Sci., 46, 617-623. doi: 10.1016/j.sbspro.2012.05.173.

Hariyati, R.T.S., Nurachmah, E., Mulyono, S. 2011. "Developing Distance Learning Method for Health Practicioner in Jakarta and Its Surroundings, Indonesia". International Journal of Education Administration and Policy Studies, 3 (11), 191-196. doi 10.5897/IJEAPS11.049. 
Inayatullah, I., Isworo, A., dan Kamaluddin, R. 2014. "Hubungan Tingkat Pendidikan Dengan Tingkat Pengetahuan Perawat Tentang Asuhan Keperawatan Dengan Pedoman NANDA, NOC, dan NIC di Rumah Sakit Umum Daerah Ajibarang". Skripsi, Universitas Jenderal Soedirman, Puwokerto.

Kautz, D.D., Kuiper, R., Pesut, D.J., dan Williams, R.L. 2006. "Using NANDA, $\mathrm{NIC}$, and NOC (NNN) Language For Clinical Reasoning With The OutcomePresentState-Test (OPT) Model". Int. J. Nurs. Terminol. Classif., 17 (3), 8-129.

Kaesmetan, R., dan Rochdiat, W.M. 2012. "Faktor-Faktor yang Berhubungan dengan Penguasaan NANDA, NOC, NIC pada Mahasiswa Keperawatan Semester VI Fakultas IImu Kesehatan Universitas Respati Yogyakarta". Jurnal Respati, 2 (1). Retrieved from: http://journal.respati. ac.id/index.php/ilmukeperawawatan/ article/view/424.

Muller-Staub, M., Lunney, M., Lavin, M.A., Needham, I., Odenbreit, M., van Achterberg, T. 2008. "Testing the Q-DIO as an Instrument to Measure the Documented Quality of Nursing Diagnoses, Interventions, and Outcomes". Int J. Nurs. Terminol. Classif., 19 (1), 7-20.
Park, J.H. 2010. NANDA-I, NOC and NIC Linkages In Nursing Care Plans For Hospitalized Patients With Congestive Heart Failure. Disertasi. The University of IOWA's, Retrieved from http://ir.uiowa.edu/cgi/viewcontent. cgi?article $=1755 \&$ context $=$ etd.

Ramdani, R., dan Murdani, K. 2014. "E-Learning sebagai Media Pelengkap Pembelajaran Konvensional Pokok Bahasan Besaran dan Satuan". Prosiding Pertemuan IImiah XXVIII HFI Jateng \& DIY 2014, 396-399.

Sukismanto dan Rahayu, G. R. (2012). Kebutuhan dan Pengembangan Pembelajaran dengan Teknologi Informasi (E-learning) di Fakultas IImu Kesehatan Universitas Respati Yogyakarta. Thesis. Universita Gadjah Mada, Yogyakarta.

Tabanan, D.I.S., Kade, N., Nita, A., Pudjawan, K., Tastra, I.D.K. 2014. "Pengembangan Media Pembelajaran E-Learning pada Pelajaran Bahasa Indonesia Siswa Kelas XI". e-Journal Edutech Universitas Pendidikan Ganesha, 1.

Yearous, G.K.S. 2010. "School Nursing Documentation: Knowledge, Attitude, And Barriers To Using Standardized Nursing Languages And Current Practices". Dissertation. The University Of IOWA, Low City IOWA. 